\title{
Edi Milos, Antun Radić (1868-1919). Homme de lettres engagé et théoricien du mouvement paysan croate
}

\section{Daniel Baric}

\section{(2) OpenEdition}

\section{Journals}

Édition électronique

URL : https://journals.openedition.org/austriaca/1545

DOI : 10.4000/austriaca.1545

ISSN : 2729-0603

\section{Éditeur}

Presses universitaires de Rouen et du Havre

\section{Édition imprimée}

Date de publication : 1 juin 2020

Pagination : 258-262

ISBN : 979-10-240-1492-0

ISSN : 0396-4590

\section{Référence électronique}

Daniel Baric, «Edi Milos, Antun Radić (1868-1919). Homme de lettres engagé et théoricien du mouvement paysan croate », Austriaca [En ligne], 90 | 2020, mis en ligne le 01 juin 2020, consulté le 12 octobre 2022. URL : http://journals.openedition.org/austriaca/1545; DOI : https://doi.org/10.4000/austriaca. 1545

Ce document a été généré automatiquement le 12 octobre 2022.

Tous droits réservés 


\title{
Edi Milos, Antun Radić (1868-1919). Homme de lettres engagé et théoricien du mouvement paysan croate
}

\author{
Daniel Baric
}

\section{RÉFÉRENCE}

Edi Milos, Antun Radić (1868-1919). Homme de lettres engagé et théoricien du mouvement paysan croate, Paris, PUPS, « Croatica Parisiensia », 2018, 586 p., ISBN : 979-10231-0594-0, $29 €$.

1 Antun Radić fait partie des figures du monde intellectuel et politique croate des dernières décennies de la monarchie habsbourgeoise. L'un des intérêts de sa biographie, issue d'une thèse soutenue sous la direction de Jean-Paul Bled en 2008, est que, dans la fratrie des Radić, ce n'est pas Antun, mais son frère cadet Stjepan (1871-1928) qui reçoit habituellement les faveurs de la recherche. Il est vrai que l'influence politique du Parti paysan croate dont ils furent les inspirateurs ne fut décisive que dans l'entre-deux-guerres, soit après la disparition d'Antun, lorsque Stjepan assura la direction du mouvement jusqu'à sa disparition en 1928. À travers la carrière d'Antun Radić, c'est la genèse austro-hongroise d'un mouvement s'épanouissant pleinement dans la monarchie yougoslave qui lui succéda qui est retracée. La monographie aborde la carrière intellectuelle de Radić dans une première partie, retrace ensuite son activité de rédacteur en chef et publiciste avant de décrire son action politique.

2 Fils de paysans pauvres, Antun Radić est né l'année de la signature du Compromis hungaro-croate ${ }^{1}$ qui vint compléter les articles du Compromis austro-hongrois de 1867. Grâce à ses efforts et à son talent, il acquit une place singulière dans le paysage intellectuel croate. Après avoir fréquenté le lycée à Zagreb, il s'inscrivit en études slaves à l'université de Vienne où il suivit les leçons de l'éminent slaviste Vatroslav 
Jagić et devint en 1893 docteur ès lettres de l'université de Zagreb. Professeur au lycée, il se consacra bientôt à l'organisation de l'ethnographie croate naissante. Il joua un rôle essentiel dans l'élaboration d'une méthodologie de cette nouvelle science, à laquelle il donna le nom (inusité de nos jours) de narodoznanstvo en s'inspirant de la Volkskunde. Au sein de l'Académie des sciences et des arts des Slaves du Sud, il mit au point un questionnaire et organisa la collecte et l'édition d'un riche matériau (qui devait être retranscrit intégralement dans le parler du locuteur), ce qui fait de lui le pionnier de l'ethnographie en Croatie. Attaché au milieu paysan d'où il était issu, il demeura sa vie durant conscient du différentiel culturel entre les campagnes et la ville et chercha des remèdes à une situation qu'il estimait dommageable.

3 La revue Dom («le foyer ») qu'il fonde commence à paraitre en 1899; il en est le principal contributeur durant les cinq premières années de parution. Le périodique s'adresse au monde rural déstabilisé par le démantèlement d'une forme structurante de la vie communautaire et familiale dans l'espace sud-slave, la zadruga. Radić développe dans sa revue une conception de la culture croate comme rameau du monde slave dont les liens doivent être renforcés, en particulier avec la culture et la littérature russes, sans pour autant exprimer de fascination pour le gouvernement et la politique russes : la certitude de la fécondité d'un rapport étroit avec le monde russe se fonde sur une méfiance à l'égard de la culture germanique.

4 Les questions culturelles apparaissent au cœur du développement d'une pensée qui aboutit à l'élaboration d'un programme d'action économique et politique. Antun Radić s'implique par exemple dans la fondation d'organismes de crédit, sur le modèle élaboré par l'économiste Friedrich Wilhelm Raiffeisen. Face à la réalité d'un monde slave morcelé, il développe par ailleurs des réflexions qui ancrent son projet politique dans l'austroslavisme. Toute la complexité de la vie politique et culturelle dans le dernier quart de siècle austro-hongrois apparaît à travers les débats sur les questions culturelles et sociales du moment auxquels il participe. Le positionnement de Radić parmi les forces politiques en présence permet de saisir l'importance de questions littéraires et artistiques, liées notamment au réalisme, au naturalisme ou à la Sécession viennoise. L'émergence des sociaux-démocrates au début des années 1890 fut l'occasion pour lui d'une mise au point sur l'importance qu'il accorde à la propriété privée et au facteur national, qui lui apparaît comme un horizon indépassable. Les polémiques par journaux interposés autour des identités serbe et croate au tournant du xxe siècle, qui culminèrent en 1902 à Zagreb par des actions violentes à l'encontre de représentants de la communauté serbe, montrent la complexité de la position de Radić, à la recherche d'une solution viable dans le cadre d'une future communauté politique. Enfin, la question du rôle de l'Église catholique se pose à lui de manière récurrente, à travers diverses questions culturelles et cultuelles (notamment la messe en slavon), alors que le clergé souhaite détourner les populations rurales d'un mouvement accusé d'anticléricalisme. La naissance du Parti populaire paysan croate (Hrvatska pučka seljačka stranka HPSS) en 1904 apparaît comme la résultante de la longue phase préparatoire retracée dans l'ouvrage, même si cet organisme politique ne reflète qu'en partie seulement, comme prend soin de le préciser le biographe, les ambitions de Radić.

5 Edi Miloš livre le bilan critique d'une carrière abruptement interrompue par la maladie, tout en prenant soin de situer les débats dans lesquels s'insèrent la pensée et l'activité de Radić dans le temps long : l'intégration de la Croatie dans l'espace habsbourgeois et les tiraillements entre loyauté et tentations de nouvelles alliances, voire d'autonomie 
ou d'indépendance. Critique d'une historiographie croate complaisamment hostile au pouvoir austro-hongrois à l'époque yougoslave (mais qui ne pouvait non plus nier que cette période ait été marquée par un fort développement économique et culturel, p. 341), l'auteur cite amplement les propos de Radić qui documentent ses réflexions méfiantes sur le rôle potentiel des femmes en politique ou sur ses adversaires politiques qui frôlent l'antisémitisme. Dans une vision empathique, mais qui ne se départit pas d'un sens critique, le personnage est replacé dans son époque: le soubassement de sa vision du monde est contextualisé, reposant, non sans idéalisation du monde rural, sur la dichotomie entre culture populaire et culture lettrée. En prenant appui sur une documentation très riche, à la fois en imprimés (l'opus de Radić comprenant à lui seul 19 volumes) et puisée dans différents fonds d'archives, Edi Miloš propose davantage que la simple biographie d'un agrarien centre-européen. À travers les réseaux, les programmes éparpillés entre différentes options politiques, les conflits personnels et les revirements, le lecteur suit pas à pas une pensée et une action en mouvement dans son époque.

6 La riche bibliographie toujours traduite et classée en sections thématiques offre un point de départ sûr pour une exploration ultérieure (on pourra regretter cependant l'absence de références aux ouvrages de Stefano Petrungaro disponibles en italien). Abordant des territoires et des périodes peu explorés par l'historiographie de langue française, des questions de terminologie se posent. L'auteur a voulu proposer certains néologismes : « croaticité » (hrvatstvo), « serbicité » (srpstvo), pour désigner une identité culturelle et nationale, parfois en concurrence avec des termes déjà entrés dans l'usage (Croatie banique pour Croatie civile, les oustaches plutôt que les oustachis). Les traductions "Théâtre territorial» pour Landestheater de Zagreb (p.93) ou «Musée territorial» pour Landesmuseum de Sarajevo (p.109) ne rendent sans doute pas pleinement le sens de Land comme province de l'Empire austro-hongrois. Des adjectifs et substantifs dérivés sont formés : radićisme et radićien, starčevićisme et starčevićiste, sans que l'on saisisse les raisons et le sens attribués à l'usage de tel suffixe. L'avenir dira si ces termes peuvent être repris, alors que leur motivation n'est pas énoncée. Dans le corps du texte, on relèvera quelques rares inexactitudes ou coquilles (Nevesinje en Herzégovine qualifié de village, p.111; la revue qu'il conviendrait d'orthographier Českýlid, p. 118).

7 Ces remarques très ponctuelles ne remettent pas en cause l'importance de cet ouvrage dans l'historiographie de langue française et au-delà, qui permet d'appréhender les complexités de la vie politique et culturelle croate particulièrement fragmentée et plus largement austro-hongroise, depuis les compromis jusqu'à la Première Guerre mondiale. Il s'avérera sans doute indispensable pour toute étude comparative qui s'efforcerait d'inscrire dans un mouvement plus vaste, à l'échelle de toute la monarchie habsbourgeoise, les débats qui agitèrent le monde croate autour de la question paysanne. Cette perspective paraît d'autant plus intéressante qu'Antun Radić semble avoir fait peu de cas des mouvements agrariens contemporains et convergents, tant en Hongrie que dans les autres contextes slaves. 


\section{NOTES}

1. Sur le texte et ses conséquences, voir Daniel Baric, «Entre construction juridique, tensions nationales et modernisation : le Compromis hungaro-croate de 1868 ", Austriaca, $\mathrm{n}^{\circ} 73$, décembre 2011, p. 31-48. 